\title{
Hybrid Crystals of Cuprates and Iron-Based Superconductors
}

\author{
Xia Dai, ${ }^{1}$ Congcong Le, ${ }^{1}$ Xianxin $\mathrm{Wu},{ }^{1}$ and Jiangping $\mathrm{Hu}^{1,2,3}$ \\ ${ }^{1}$ Institute of Physics, Chinese Academy of Sciences, Beijing 100190, China \\ ${ }^{2}$ Collaborative Innovation Center of Quantum Matter, Beijing, China \\ ${ }^{3}$ Department of Physics, Purdue University, West Lafayette, Indiana 47907, USA
}

(Dated: October 4, 2018)

\begin{abstract}
We propose two possible new compounds, $\mathrm{Ba}_{2} \mathrm{CuO}_{2} \mathrm{Fe}_{2} \mathrm{As}_{2}$ and $\mathrm{K}_{2} \mathrm{CuO}_{2} \mathrm{Fe}_{2} \mathrm{Se}_{2}$, which hybridize the building blocks of two high temperature superconductors, cuprates and iron-based superconductors. These compounds consist of square $\mathrm{CuO}_{2}$ layers and antifluorite-type $\mathrm{Fe}_{2} \mathrm{X}_{2}(\mathrm{X}=\mathrm{As}, \mathrm{Se})$ layers separated by $\mathrm{Ba} / \mathrm{K}$. The calculations of binding energies and phonon spectrums indicate that they are dynamically stable, which ensures that they may be experimentally synthesized. The Fermi surfaces and electronic structures of the two compounds inherit the characteristics of both cuprates and iron-based superconductors. These compounds can be superconductors with intriguing physical properties to help to determine pairing mechanisms of high $T_{c}$ superconductivity.

PACS numbers: 74.70.Xa, 61.50.-f, 75.50.Bb, 71.15.Mb
\end{abstract}

\section{INTRODUCTION}

Cuprates $^{1-8}$, first discovered in 1986, and iron-based superconductors ${ }^{9-13}$ (IBS), discovered in early 2008, are two classes of unconventional high temperature superconductors who share many common features. Both of them are quasi-two-dimensional and the phase diagrams are similar in which superconductivity develops after a magnetic order is suppressed ${ }^{14-16}$. All the cuprates share a common structure element $\mathrm{CuO}_{2}$ plane, where $\mathrm{Cu}$ atoms form a square lattice ${ }^{17}$. The IBS share a common $\mathrm{Fe}_{2} \mathrm{X}_{2}(\mathrm{X}=\mathrm{As}$ and $\mathrm{Se}$ ) layered structure unit, which possesses an anti-PbO-type (anti-lithargetype) atom arrangement. The $\mathrm{Fe}_{2} \mathrm{X}_{2}$ layers consist of a square lattice sheet of $\mathrm{Fe}$ coordinated by $\mathrm{X}$ above and below the plane to form face sharing $\mathrm{FeX}_{4}$ tetrahedra ${ }^{18}$.

One of major questions in the field of high $T_{c}$ superconductors is whether cuprates and IBS share a common superconducting mechanism ${ }^{16,19}$. The answer to this question may be obtained if we can integrate the characteristics of both superconductors into a single compound so that their relations can be exclusively addressed. As both structures are featured with layered square lattices with similar in-plane lattice constants, it is possible to design a compound containing both building blocks, $\mathrm{Cu}-\mathrm{O}$ layers of cuprates and $\mathrm{Fe}-\mathrm{As}(\mathrm{Se})$ layers of IBS. A similar material design has been adopted and a target material $\mathrm{Nd}_{4} \mathrm{CuO}_{6} \mathrm{Fe}_{2} \mathrm{As}_{2}$ has been theoretically investigated ${ }^{20}$.

Recently, two new materials $\mathrm{Ba}_{2} \mathrm{MO}_{2} \mathrm{Ag}_{2} \mathrm{Se}_{2}$ (M = $\mathrm{Co}, \mathrm{Mn})^{21}$ have been synthesized via solid-state reaction in experiment. These two compounds, whose structures belong to I4/mmm space group, consist of infinite $\mathrm{MO}_{2}$ square planes and antifluorite-type $\mathrm{Ag}_{2} \mathrm{Se}_{2}$ layers separated by barium. In this paper, motivated by the fact that the $\mathrm{MO}_{2}$ plane resembles the $\mathrm{CuO}_{2}$ plane in cuprates and the $\mathrm{Ag}_{2} \mathrm{Se}_{2}$ layer resembles the $\mathrm{Fe}_{2} \mathrm{X}_{2}$ layer in IBS, we consider the substitution of $\mathrm{Cu}$ and $\mathrm{Fe}$ for $\mathrm{M}$ and $\mathrm{Ag}$ in the compounds respectively to obtain two possible new compounds, $\mathrm{Ba}_{2} \mathrm{CuO}_{2} \mathrm{Fe}_{2} \mathrm{As}_{2}$ and $\mathrm{K}_{2} \mathrm{CuO}_{2} \mathrm{Fe}_{2} \mathrm{Se}_{2}$. We perform density functional calculations to study the stability and basic electronic structures of these new compounds. We find that these materials integrate basic electronic characteristics of both high $T_{c}$ superconductors. In
$\mathrm{Ba}_{2} \mathrm{CuO}_{2} \mathrm{Fe}_{2} \mathrm{As}_{2}$, the $\mathrm{CuO}_{2}$ layers are electron-doped while the $\mathrm{Fe}_{2} \mathrm{As}_{2}$ layers are hole-doped. The situation is reversed in $\mathrm{K}_{2} \mathrm{CuO}_{2} \mathrm{Fe}_{2} \mathrm{Se}_{2}$. Such doping configurations suggest that many possible mixed phases, in particular, magnetic and superconducting phases, may be realized in these materials by introducing additional carriers and applying external pressure.

\section{COMPUTATIONAL DETAILS}

Our calculations are performed using density functional theory (DFT) employing the projector augmented wave (PAW) method encoded in the Vienna ab initio simulation package (VASP) ${ }^{22-24}$. Both of the local density approximation (LDA) and generalized-gradient approximation (GGA) ${ }^{25}$ for the exchange correlation functional are used. Throughout the work, the cutoff energy is set to be $500 \mathrm{eV}$ for expanding the wave functions into plane-wave basis. In the calculations of magnetic properties, the LDA+U method is used with the effective on-site Coulomb $\mathrm{U}$ being $7 \mathrm{eV}$ for $\mathrm{Cu} 3 d$ states $^{26}$. In the calculations, the Brillouin zone is sampled in the $\mathbf{k}$ space within Monkhorst-Pcak scheme ${ }^{27}$. The number of these $k$ points are depending on the lattice: $15 \times 15 \times 3$ for the general unit cell with $4 \mathrm{Fe}$ atoms and $2 \mathrm{Cu}$ atoms and $9 \times 9 \times 3$ for the $\sqrt{2} \times \sqrt{2}$ unit cell. We relax the lattice constants and internal atomic positions with both LDA and GGA, where forces are minimized to less than $0.01 \mathrm{eV} / \AA$. The phonon dispersions are calculated using finite displacement method ${ }^{28}$ as implemented in the PHONOPY code $^{29,30}$.

\section{CRYSTAL STRUCTURE}

$\mathrm{Ba}_{2} \mathrm{CuO}_{2} \mathrm{Fe}_{2} \mathrm{As}_{2}$ and $\mathrm{K}_{2} \mathrm{CuO}_{2} \mathrm{Fe}_{2} \mathrm{Se}_{2}$ crystallize in a bodycentered tetragonal lattice, shown in Figure 1. The $\mathrm{Ba}(\mathrm{K})$ spacer layer separates the tetrahedra6l $\mathrm{Fe}_{2} \mathrm{As}_{2}\left(\mathrm{Fe}_{2} \mathrm{Se}_{2}\right)$ layers and the square $\mathrm{CuO}_{2}$ layers. There are double $\mathrm{Fe}_{2} \mathrm{X}_{2}(\mathrm{X}=\mathrm{As}$ and $\mathrm{Se}$ ) and $\mathrm{CuO}_{2}$ layers in a unit cell, similar to $\mathrm{BaFe}_{2} \mathrm{As}_{2}$. In order to predict the structures of $\mathrm{Ba}_{2} \mathrm{CuO}_{2} \mathrm{Fe}_{2} \mathrm{As}_{2}$ and $\mathrm{K}_{2} \mathrm{CuO}_{2} \mathrm{Fe}_{2} \mathrm{Se}_{2}$, the lattices are fully optimized based on the 


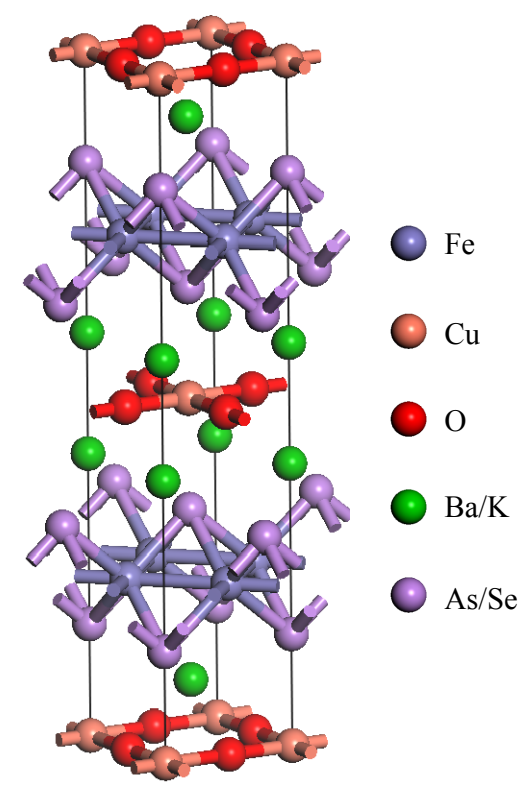

FIG. 1: (color online) Crystal structure of $\mathrm{Ba}_{2} \mathrm{CuO}_{2} \mathrm{Fe}_{2} \mathrm{As}_{2}$ $\left(\mathrm{K}_{2} \mathrm{CuO}_{2} \mathrm{Fe}_{2} \mathrm{Se}_{2}\right)$.

experimental structural parameters of $\mathrm{Ba}_{2} \mathrm{CoO}_{2} \mathrm{Ag}_{2} \mathrm{Se}_{2}$. The optimized and experimental structural parameters are summarized in Table I. Both of the calculated lattice constants using LDA and GGA are close to those of $\mathrm{Ba}_{2} \mathrm{CoO}_{2} \mathrm{Ag}_{2} \mathrm{Se}_{2}$ in experiment, which validates the adopted substitution. As the calculated lattice parameters for $\mathrm{Ba}_{2} \mathrm{CoO}_{2} \mathrm{Ag}_{2} \mathrm{Se}_{2}$ using GGA are closer to the experimental data, we perform the following calculations for the two materials using the lattice parameters obtained by relaxation with GGA.

The binding energy is usually calculated to estimate the stability of new structures. Here, the binding energy per atom, $E_{b}$, is defined as $E_{b}=\left(4 E_{B a / K}+2 E_{C u}+4 E_{O}+4 E_{F e}+\right.$ $\left.4 E_{A s / S e}-E_{\text {total }}\right) / 18$, in which $E_{B a}, E_{K}, E_{C u}, E_{O}, E_{F e}, E_{A s}$ and $E_{S e}$ are the respective energies per atom of elemental $\mathrm{Ba}, \mathrm{K}, \mathrm{Cu}, \mathrm{O}, \mathrm{Fe}, \mathrm{As}$ and $\mathrm{Se}$ in the states at standard ambient temperature and pressure. $E_{\text {total }}$ is the calculated total energy of a unit cell of $\mathrm{Ba}_{2} \mathrm{CuO}_{2} \mathrm{Fe}_{2} \mathrm{As}_{2}\left(\mathrm{~K}_{2} \mathrm{CuO}_{2} \mathrm{Fe}_{2} \mathrm{Se}_{2}\right)$. The obtained binding energies are $1.61 \mathrm{eV}$ and $1.23 \mathrm{eV}$ per atom for $\mathrm{Ba}_{2} \mathrm{CuO}_{2} \mathrm{Fe}_{2} \mathrm{As}_{2}$ and $\mathrm{K}_{2} \mathrm{CuO}_{2} \mathrm{Fe}_{2} \mathrm{Se}_{2}$, respectively. Both of the binding energies are very close to that of $\mathrm{Ba}_{2} \mathrm{CoO}_{2} \mathrm{Ag}_{2} \mathrm{Se}_{2}(1.318 \mathrm{eV})$, indicating that the two structures are energetically favorable in experiment and may be synthesized using similar methods. To further test the stability of these two structures, we calculate their phonon dispersions, shown in Figure 2. No imaginary frequencies are observed throughout the whole Brillouin zone in phonon dispersions, confirming their dynamically structural stability.

\section{ELECTRONIC AND MAGNETIC PROPERTIES}

The optimized parameter $a$ of $\mathrm{Ba}_{2} \mathrm{CuO}_{2} \mathrm{Fe}_{2} \mathrm{As}_{2}$ is determined to be $4.026 \AA$, slightly bigger than those of cuprates (3.78 $\AA$ for $\mathrm{La}_{1.8} \mathrm{Sr}_{0.2} \mathrm{CuO}_{4}{ }^{3}$ and $3.859 \AA$ for
TABLE I: Optimized structural parameters of $\mathrm{Ba}_{2} \mathrm{CuO}_{2} \mathrm{Fe}_{2} \mathrm{As}_{2}$ and $\mathrm{K}_{2} \mathrm{CuO}_{2} \mathrm{Fe}_{2} \mathrm{Se}_{2}$, using LDA and GGA in the paramagnetic phase. The 6th column is the experimental structural parameters of $\mathrm{Ba}_{2} \mathrm{CoO}_{2} \mathrm{Ag}_{2} \mathrm{Se}_{2}{ }^{21}$.

\begin{tabular}{c|cc|cc|c}
\hline \hline & \multicolumn{2}{|c|}{$\mathrm{Ba}_{2} \mathrm{CuO}_{2} \mathrm{Fe}_{2} \mathrm{As}_{2}$} & \multicolumn{2}{|c|}{$\mathrm{K}_{2} \mathrm{CuO}_{2} \mathrm{Fe}_{2} \mathrm{Se}_{2}$} & $\mathrm{Ba}_{2} \mathrm{CoO}_{2} \mathrm{Ag}_{2} \mathrm{Se}_{2}$ \\
\hline & LDA & GGA & LDA & GGA & Expt. \\
\hline$a(\AA)$ & 3.902 & 4.026 & 3.769 & 3.839 & 4.223 \\
$c(\AA)$ & 19.867 & 20.273 & 18.320 & 22.165 & 20.036 \\
\hline \hline
\end{tabular}

(a)

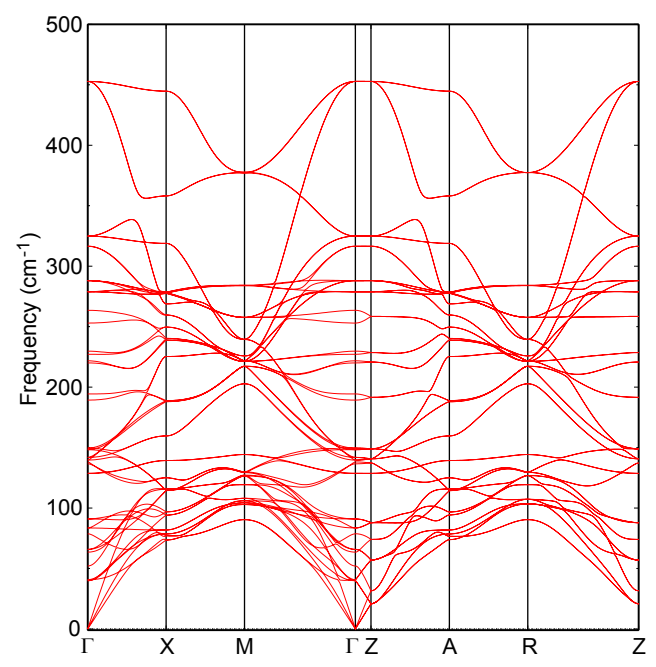

(b)

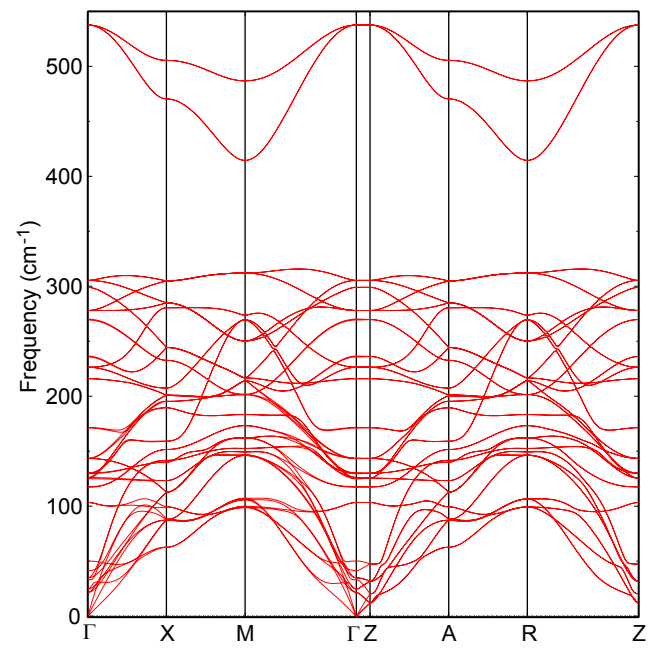

FIG. 2: (color online) Calculated GGA phonon dispersions of $\mathrm{Ba}_{2} \mathrm{CuO}_{2} \mathrm{Fe}_{2} \mathrm{As}_{2}$ and $\mathrm{K}_{2} \mathrm{CuO}_{2} \mathrm{Fe}_{2} \mathrm{Se}_{2}$ in the paramagnetic state.

TABLE II: Optimized structural parameters of $\mathrm{Ba}_{2} \mathrm{CuO}_{2} \mathrm{Fe}_{2} \mathrm{As}_{2}$ using GGA in the paramagnetic phases and those of $\mathrm{LiFeAs}^{10}$, $\mathrm{BaFe}_{2} \mathrm{As}_{2}{ }^{11}$ and $\mathrm{LaFeAsO}^{9}$. The angle $\beta$ is the Fe-As-Fe bonding angle of two next nearest $\mathrm{Fe}$ atoms.

\begin{tabular}{ccccc}
\hline \hline & $\mathrm{Ba}_{2} \mathrm{CuO}_{2} \mathrm{Fe}_{2} \mathrm{As}_{2}$ & $\mathrm{LiFeAs}$ & $\mathrm{BaFe}_{2} \mathrm{As}_{2}$ & $\mathrm{LaFeAsO}$ \\
\hline$a(\AA)$ & 4.026 & 3.791 & 3.963 & 4.035 \\
$\beta(\circ)$ & 118.7 & 103.1 & 111.0 & 113.5 \\
$\mathrm{~h}(\mathrm{Fe}-\mathrm{As})(\AA)$ & 1.19 & 1.51 & 1.36 & 1.32 \\
$\mathrm{~h}(\mathrm{Fe}-\mathrm{Fe})(\AA)$ & 10.14 & 6.36 & 6.51 & 8.74 \\
\hline \hline
\end{tabular}


$\mathrm{YBa}_{2} \mathrm{Cu}_{3} \mathrm{O}_{6+x}{ }^{4}$ ). Compared with three typical kind of iron pnictides, $\mathrm{LiFeAs}^{10}, \mathrm{BaFe}_{2} \mathrm{As}_{2}{ }^{11}$, and $\mathrm{LaFeAsO}^{9}$, as shown in Table II, the parameter $a$ is very close to those of $\mathrm{BaFe}_{2} \mathrm{As}_{2}$ and $\mathrm{LaFeAsO}$ but deviates a little from that of LiFeAs. The obtained As height above the Fe plane in $\mathrm{Ba}_{2} \mathrm{CuO}_{2} \mathrm{Fe}_{2} \mathrm{As}_{2}$ is smaller than those of iron pnictides in experiment. This underestimation has been noted in the study of IBS $^{31-33}$. The $\mathrm{Fe}_{2} \mathrm{As}_{2}$ inter-layer distance is much larger than the values of the three families in iron pnictides, indicating that it is more two-dimensional than conventional iron pnictides. The separation between $\mathrm{Fe}_{2} \mathrm{As}_{2}$ and $\mathrm{CuO}_{2}$ layers is about $5 \AA$, which suggests couplings between these layers.

The band structure and density of states (DOS) for $\mathrm{Ba}_{2} \mathrm{CuO}_{2} \mathrm{Fe}_{2} \mathrm{As}_{2}$ with GGA optimized structural parameters in the paramagnetic states are shown in Figure 3. The band structure near the Fermi level resembles those of both typical iron pnictides $\mathrm{LaFeAsO}^{34}$ and cuprates ${ }^{14}$ where $\mathrm{Fe} 3 \mathrm{~d}$ states $\left(d_{x z}, d_{y z}, d_{x^{2}-y^{2}}\right.$ orbitals) and $\mathrm{Cu} 3 \mathrm{~d}$ states $\left(d_{x^{2}-y^{2}}\right.$ orbitals) dominate the Fermi level. Similar to iron pnictides, it is a bad metal with low carrier density. The $3 d$ states of Fe are mainly located near the Fermi level from $-2.5 \mathrm{eV}$ to $3.0 \mathrm{eV}$ and a pseudogap appears at an electron count of six. The As $p$ states mainly lie $2.5 \mathrm{eV}$ below the Fermi level but slightly mix with the $\mathrm{Fe} 3 d$ states in the energy range from $-1.0 \mathrm{eV}$ to $1.0 \mathrm{eV}$. The $\mathrm{Cu} 3 d$ contribution is concentrated between $-3.0 \mathrm{eV}$ and $1.5 \mathrm{eV}$. The $\mathrm{O} p$ states are strongly coupled with $3 d$ states of $\mathrm{Cu}$ in the total energy range. The spacer layer $\mathrm{Ba} 5 d$ and $6 s$ states, which donate electrons to $\mathrm{Fe}_{2} \mathrm{As}_{2}$ and $\mathrm{CuO}_{2}$ layers, are empty and lie $2 \mathrm{eV}$ above the Fermi level. At the Fermi level, the total DOS shows the same negative slope with the minimum slightly above the Fermi level, similar to the conventional IBS within DFT. The DOS at the Fermi energy is about $7.81 \mathrm{eV}^{-1} /$ f.u. for both spins. Considering that there are two $\mathrm{Fe}$ atoms in one formula unit for $\mathrm{Ba}_{2} \mathrm{CuO}_{2} \mathrm{Fe}_{2} \mathrm{As}_{2}$ but only one for $\mathrm{LaFeAsO}$, this value $\left(3.91 \mathrm{eV}^{-1} / \mathrm{Fe}\right)$ is larger than that of $\mathrm{LaFeAsO}\left(2.62 \mathrm{eV}^{-1} /\right.$ f.u. $\left.^{34}\right)$. The corresponding Pauli susceptibility and specific heat coefficient are $\chi_{0}=2.53 \times 10^{-4}$ $\mathrm{emu} / \mathrm{mol}$ and $\gamma=18.4 \mathrm{~mJ} /\left(K^{2} \mathrm{~mol}\right)$.

The calculated Fermi surfaces of $\mathrm{Ba}_{2} \mathrm{CuO}_{2} \mathrm{Fe}_{2} \mathrm{As}_{2}$ are given in Figure 4, which are very similar to those of both iron pnictides and cuprates. From Figure 3(a), we find that the $\mathrm{Fe}$ $d_{x z}$ and $d_{y z}$ states yield two hole cylinders at the zone center. There is an additional heavy $3 \mathrm{D}$ hole pocket centered at $\Gamma$ point, which intersects and anticrosses with the hole cylinders. The 3D pocket is derived from Fe $d_{z^{2}}$ states which hybridize with As $p_{z}$ states. At the zone corner, there are two 2D small electron pockets and one 2D large hole pocket. The electron pockets are mainly attributed to $\mathrm{Fe} d_{x z}, d_{y z}$ and $d_{x^{2}-y^{2}}$ orbitals $\left(d_{x y}\right.$ orbitals in usual Fe lattice). The hole pocket around $\mathrm{M}$ point, however, is mainly derived from $\mathrm{Cu} d_{x^{2}-y^{2}}$ and $\mathrm{O}$ $p_{x}$ and $p_{y}$ states, in accordance with the Fermi surfaces of cuprates $^{14}$. All of the Fermi surface sheets are double degenerate as there are two $\mathrm{Fe}_{2} \mathrm{As}_{2}$ and $\mathrm{CuO}_{2}$ layers in one unit cell.

It is interesting to see that the hole pockets at $\Gamma$ point are large, which indicates heavy hole doping in the $\mathrm{Fe}_{2} \mathrm{As}_{2}$ layers. From the size of the pockets, we can estimate that the hole doping concentration with respect to $\mathrm{BaFe}_{2} \mathrm{As}_{2}$ is roughly (a)

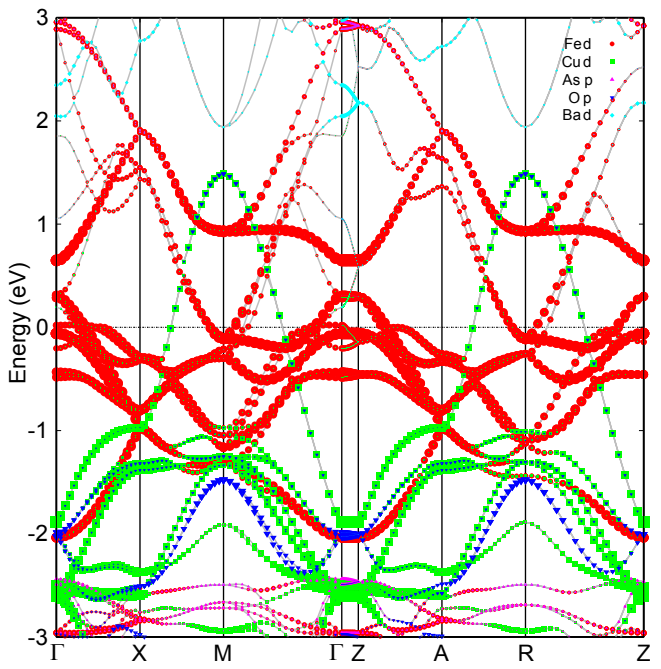

(b)

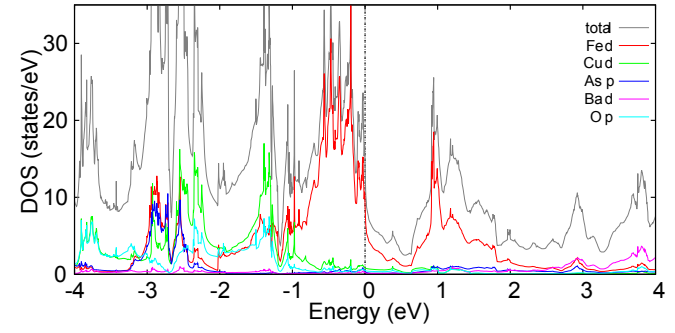

FIG. 3: (color online) Band structures and projected density of states of $\mathrm{Ba}_{2} \mathrm{CuO}_{2} \mathrm{Fe}_{2} \mathrm{As}_{2}$ using GGA relaxed parameters in the paramagnetic state.

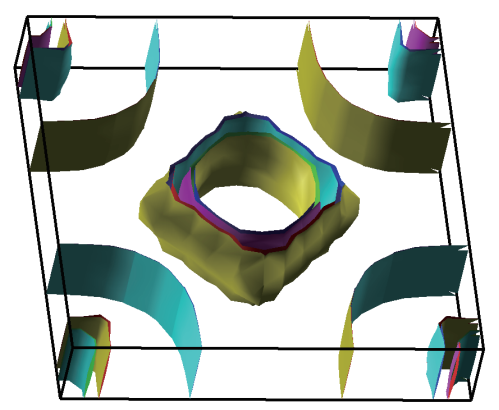

FIG. 4: (color online) Calculated Fermi surfaces of $\mathrm{Ba}_{2} \mathrm{CuO}_{2} \mathrm{Fe}_{2} \mathrm{As}_{2}$ using GGA relaxed parameters in the paramagnetic state.

0.15 holes per Fe atom. Considering the hole doping level, the Fermi surfaces attributed to $\mathrm{Fe}_{2} \mathrm{As}_{2}$ layers should be similar to $\mathrm{Ba}_{0.7} \mathrm{~K}_{0.3} \mathrm{Fe}_{2} \mathrm{As}_{2}$ except that the pockets here are much more two-dimensional. This hole doping level is very close to that in optimally-hole-doped pnictide $\mathrm{Ba}_{0.6} \mathrm{~K}_{0.4} \mathrm{Fe}_{2} \mathrm{As}_{2}{ }^{35-37}$ where $T_{c}$ can reach $37 \mathrm{~K}$. Actually, the calculated Fermi surfaces are similar to those of $(\mathrm{Ba}, \mathrm{K}) \mathrm{Fe}_{2} \mathrm{As}_{2}$ obtained in ARPES experiment ${ }^{38,39}$. As required by the charge conservation, the heavy hole doping in $\mathrm{Fe}_{2} \mathrm{As}_{2}$ layers suggests that $\mathrm{CuO}_{2}$ layers must be heavily electron-doped with the same doping concentration. This consistency is confirmed by the estimation that the size of the largest hole pocket at M point attributed to 
$d_{x^{2}-y^{2}}$ orbitals in $\mathrm{CuO}_{2}$ layers is about 0.3 electrons per $\mathrm{Cu}$ atom from their half filling configuration. The doping level is a little far from narrow superconducting region for electrondoped cuprates in the phase diagram ${ }^{14}$.

The superconductivity in both cuprates and IBS is mostly likely related to the magnetism. Therefore, we investigate the magnetic properties for this new compound. With such a large doping in the $\mathrm{Fe}_{2} \mathrm{As}_{2}$ and $\mathrm{CuO}_{2}$ layers, it is expected that the checkboard antiferromagnetic (AFM) order in the $\mathrm{CuO}_{2}$ layers and the E-type collinear AFM order in $\mathrm{Fe}_{2} \mathrm{As}_{2}$ layers should be significantly weakened or completely suppressed even in the meanfield type of DFT calculations. To check this, we consider four possible magnetic states for $\mathrm{Fe}_{2} \mathrm{As}_{2}$ and $\mathrm{CuO}_{2}$ layers: paramagnetic state, ferromagnetic state, checkerboard AFM state and collinear AFM state. We calculated the total energies of these magnetic states using the $\mathrm{LDA}+\mathrm{U}$ approach. The calculations show that there is no statically ordered moment in $\mathrm{CuO}_{2}$ layers while the E-type collinear AFM order in $\mathrm{Fe}_{2} \mathrm{As}_{2}$ layers is still possible. We find that in the DFT result, the E-type state has an energy gain of $103.5 \mathrm{meV} / \mathrm{f}$.u. relative to the paramagnetic state and a spin moment of $1.59 \mu_{B}$ for each Fe. It is known that magnetic moments calculated on the known parent compounds of IBS, for example, $\mathrm{BaFe}_{2} \mathrm{As}_{2}$, is typically over $2.0 \mu_{B}{ }^{33,40}$. This moment value is significantly lowered, which is consistent with our expectation as $\mathrm{Fe}_{2} \mathrm{As}_{2}$ layers are overdoped by holes. Figure 5 (a) and (b) show the calculated band structure and DOS in the E-type collinear AFM state (with $\sqrt{2} \times \sqrt{2}$ supercell) with internal coordinates fixed to the values obtained by non-spin-polarized energy minimization. The Etype state is still metallic with low carrier concentration and $\mathrm{N}\left(E_{F}\right)$ decreases severely. Among the considered magnetic states above, the checkerboard AFM state in $\mathrm{Fe}_{2} \mathrm{As}_{2}$ layers is found to be metastable state relative to the E-type collinear AFM state. The energy gain is $81.5 \mathrm{meV} / \mathrm{f}$.u. relative to the paramagnetic state and the magnetic moment is about $1.58 \mu_{B}$ for each $\mathrm{Fe}$ atom.

With the substitution of $\mathrm{As}$ by $\mathrm{Se}$ and $\mathrm{Ba}$ by $\mathrm{K}$ in $\mathrm{Ba}_{2} \mathrm{CuO}_{2} \mathrm{Fe}_{2} \mathrm{As}_{2}$, we obtain a new compound $\mathrm{K}_{2} \mathrm{CuO}_{2} \mathrm{Fe}_{2} \mathrm{Se}_{2}$. Compared with $\mathrm{Ba}_{2} \mathrm{CuO}_{2} \mathrm{Fe}_{2} \mathrm{As}_{2}$, the parameter $a$ decreases to $3.839 \AA$ but $c$ increases to $22.165 \AA$, which is consistent with those of iron chalcogenides. Table III lists the calculated lattice parameters using GGA and those of $\mathrm{KFe}_{2} \mathrm{Se}_{2}{ }^{13}$ and $\mathrm{FeSe}^{41}$. The calculated Se height and Se-FeSe bond angle are very close to the values of FeSe, indicating that they may share some common electronic and magnetic properties. The Se heights are severely underestimated in the calculations compared with those in experiment ${ }^{42}$. The band structure and DOS are shown in Figure 6. The band structure is similar to that of $\mathrm{Ba}_{2} \mathrm{CuO}_{2} \mathrm{Fe}_{2} \mathrm{As}_{2}$. The DOS between $-2.5 \mathrm{eV}$ and $2.0 \mathrm{eV}$ is dominated by $\mathrm{Fe} 3 d$ states and Se $3 p$ states are mainly located $3.5 \mathrm{eV}$ below the Fermi level. The $\mathrm{Cu} 3 d$ states and $\mathrm{O} 2 p$ states are strongly coupled from $-4.0 \mathrm{eV}$ to $2.5 \mathrm{eV}$. The $\mathrm{K}$ atoms have no contribution to the bands near the Fermi level. To analyze the orbital characters near the Fermi level, we plot the fat band, shown in Figure 6(a). The DOS at the Fermi level is $4.54 \mathrm{eV}^{-1} /$ f.u., which is significantly lower than that of $\mathrm{Ba}_{2} \mathrm{CuO}_{2} \mathrm{Fe}_{2} \mathrm{As}_{2}$. (a)

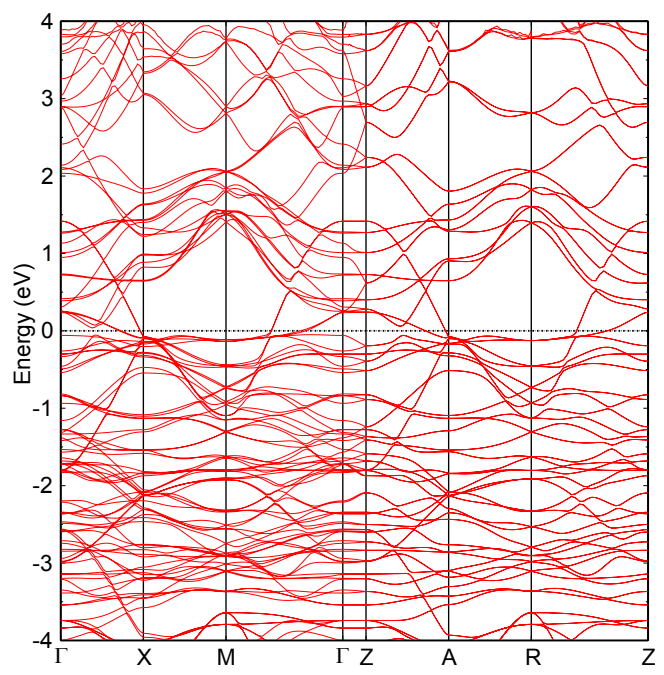

(b)

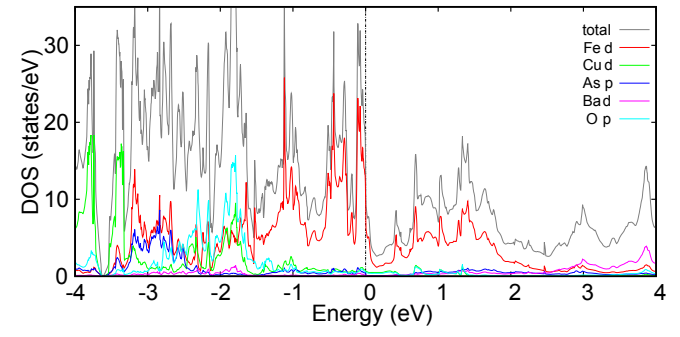

FIG. 5: (color online) Band structures and projected density of states of $\mathrm{Ba}_{2} \mathrm{CuO}_{2} \mathrm{Fe}_{2} \mathrm{As}_{2}$ using GGA relaxed parameters in the E-type collinear AFM state.

TABLE III: Optimized structural parameters of $\mathrm{K}_{2} \mathrm{CuO}_{2} \mathrm{Fe}_{2} \mathrm{Se}_{2}$ using GGA in the paramagnetic phases and those of $\mathrm{KFe}_{2} \mathrm{Se}_{2}{ }^{13}$ and $\mathrm{FeSe}^{41}$. The angle $\beta$ is the Fe-Se-Fe bonding angle of two next nearest Fe atoms.

\begin{tabular}{cccc}
\hline \hline & $\mathrm{K}_{2} \mathrm{CuO}_{2} \mathrm{Fe}_{2} \mathrm{Se}_{2}$ & $\mathrm{KFe}_{2} \mathrm{Se}_{2}$ & $\mathrm{FeSe}$ \\
\hline$a(\AA)$ & 3.839 & 3.913 & 3.765 \\
$\beta(\circ)$ & 111.6 & 106.6 & 111.3 \\
$\mathrm{~h}(\mathrm{Fe}-\mathrm{Se})(\AA)$ & 1.31 & 1.46 & 1.29 \\
$\mathrm{~h}(\mathrm{Fe}-\mathrm{Fe})(\AA)$ & 11.08 & 7.02 & 5.52 \\
\hline \hline
\end{tabular}

The corresponding Pauli susceptibility and specific heat coefficient are $\chi_{0}=1.47 \times 10^{-4} \mathrm{emu} / \mathrm{mol}$ and $\gamma=10.7$ $\mathrm{mJ} /\left(K^{2} \mathrm{~mol}\right)$. Figure 7 shows the calculated Fermi surfaces. The Fermi surfaces are two-dimensional cylinders. The Fe $3 d$ states yield two hole pockets at $\Gamma$ point and two small electron pockets at $\mathrm{M}$ point. The hole pockets are attributed to $d_{x z}$ and $d_{y z}$ states while the electron pockets are derived from $\mathrm{Fe} d_{x z}, d_{y z}$ and $d_{x^{2}-y^{2}}$ states. The Fermi surfaces are similar to those in $\mathrm{KFe}_{2} \mathrm{Se}_{2}$ where hole pockets are absent ${ }^{43}$. Besides of pockets from $\mathrm{Fe}_{2} \mathrm{Se}_{2}$ layers, there are additional two hole pockets around the Brillouin zone corners. The bigger pocket is mainly contributed from $\mathrm{Cu} d_{x^{2}-y^{2}}$ states, which are strongly coupled with the $\mathrm{O} p_{x}$ and $p_{y}$ states, while the smaller one is derived from $\mathrm{O} p_{x}$ and $p_{y}$ states. All of the Fermi surface sheets are double degenerate just as those in $\mathrm{Ba}_{2} \mathrm{CuO}_{2} \mathrm{Fe}_{2} \mathrm{As}_{2}$. 
(a)

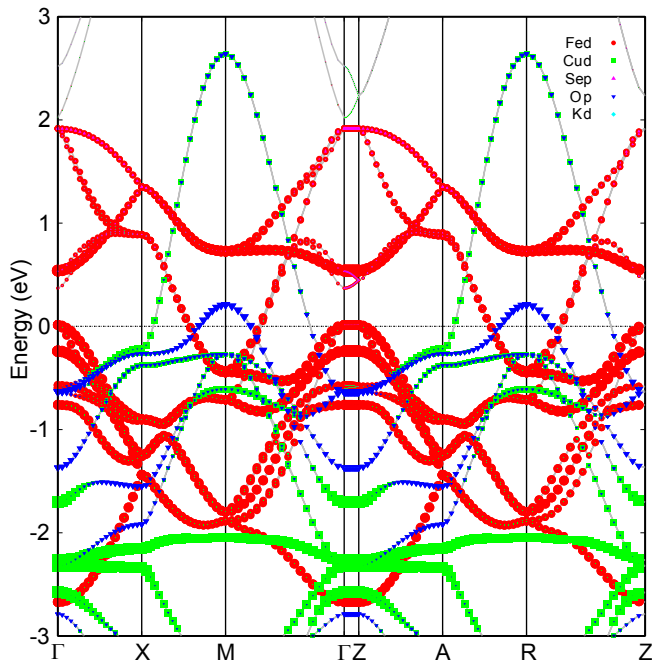

(b)

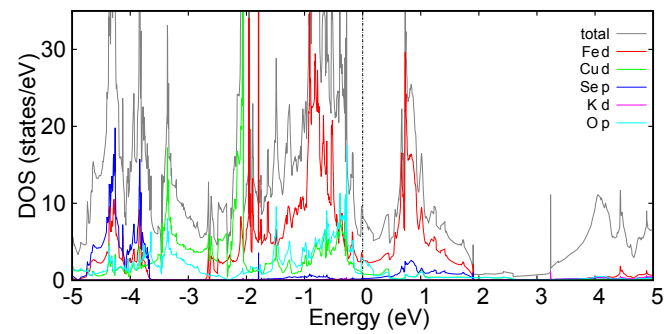

FIG. 6: (color online) Band structures and projected density of states of $\mathrm{K}_{2} \mathrm{CuO}_{2} \mathrm{Fe}_{2} \mathrm{Se}_{2}$ using GGA relaxed parameters in the paramagnetic state.

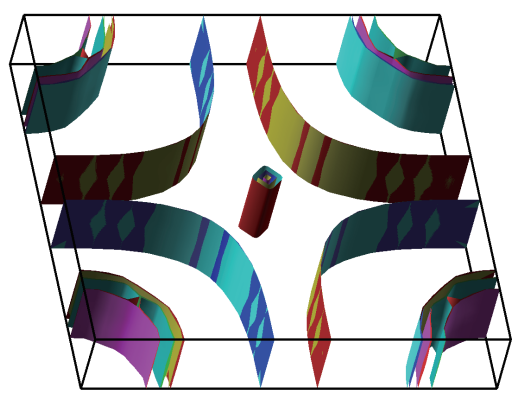

FIG. 7: (color online) Calculated Fermi surfaces of $\mathrm{K}_{2} \mathrm{CuO}_{2} \mathrm{Fe}_{2} \mathrm{Se}_{2}$ using GGA relaxed parameters in the paramagnetic state.

Compared with the Fermi surfaces of $\mathrm{Ba}_{2} \mathrm{CuO}_{2} \mathrm{Fe}_{2} \mathrm{As}_{2}$, we find that the hole pockets at $\Gamma$ point of $\mathrm{K}_{2} \mathrm{CuO}_{2} \mathrm{Fe}_{2} \mathrm{Se}_{2}$ are much smaller while the electron pockets at $\mathrm{M}$ point are much larger (see Figure 7), which indicate heavy electron doping in the $\mathrm{Fe}_{2} \mathrm{Se}_{2}$ layer. From the size of the pockets, we can estimate that the electron doping concentration with respect to $\mathrm{FeSe}$ is roughly 0.16 electrons per Fe atom. Similarly, we can check the consistency required by the charge conservation. The size of the hole pockets at $\mathrm{M}$ point from $\mathrm{CuO}_{2}$ layers is about 0.32 holes for each $\mathrm{CuO}_{2}$ layer from their half filling configuration.

The DOS at the Fermi level attributed to Fe 3d orbitals is significantly decreased with such a large electron doping, (a)

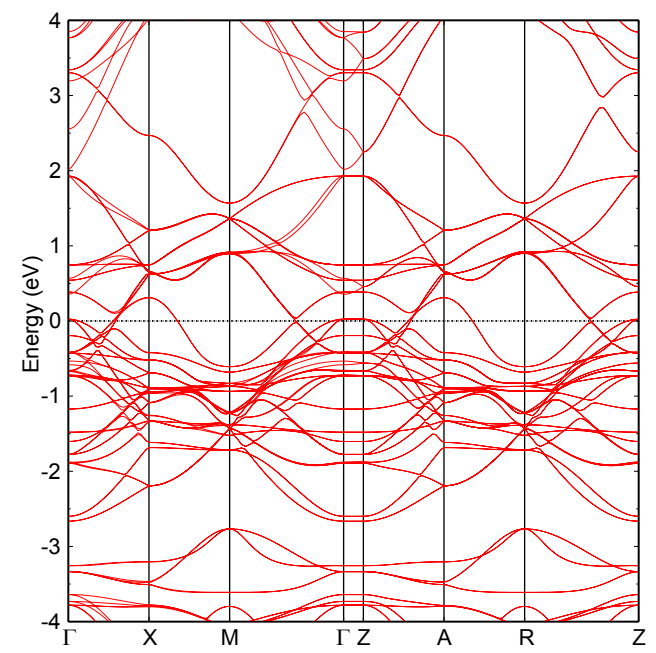

(b)

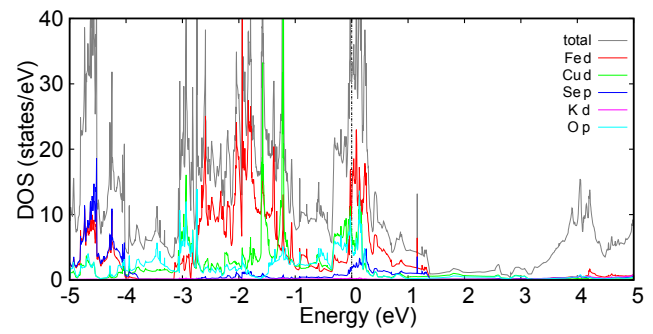

FIG. 8: (color online) Band structures and projected density of states of $\mathrm{K}_{2} \mathrm{CuO}_{2} \mathrm{Fe}_{2} \mathrm{Se}_{2}$ using GGA relaxed parameters in the AFM state.

which may suggest that magnetic order in $\mathrm{Fe}_{2} \mathrm{Se}_{2}$ layers is strongly suppressed. Compared with $\mathrm{Ba}_{2} \mathrm{CuO}_{2} \mathrm{Fe}_{2} \mathrm{As}_{2}$, we consider an additional bicollinear magnetic state, which is the ground state in $\mathrm{FeTe}^{44}$. The ground state is paramagnetic on $\mathrm{Fe}_{2} \mathrm{Se}_{2}$ layers and checkboard AFM ordered for $\mathrm{CuO}_{2}$ layers with a energy gain of $196.0 \mathrm{meV} / \mathrm{f}$.u. and a spin moment of $0.59 \mu_{B}$ per $\mathrm{Cu}$. The band structure and DOS are shown in Figure 8 and the system remains metallic. In this case, the $\mathrm{Fe}$ $3 d, \mathrm{Cu} 3 d$ and $\mathrm{O} 2 p$ states dominate the Fermi level. The DOS at the Fermi level is $7.04 \mathrm{eV}^{-1} /$ f.u. for spin up channel.

\section{DISCUSSION}

It is well known that the pairing symmetry is $d$-wave for the cuprates and $s$-wave for iron pnictides with a potential sign change between the hole and electron Fermi pockets. As the proposed new materials contain both $\mathrm{CuO}_{2}$ layers and $\mathrm{Fe}_{2} \mathrm{X}_{2}(\mathrm{X}=\mathrm{As}, \mathrm{Se})$ layers and the electronic structures are similar to both, it can be expected that two different pairing symmetries may coexist in a single material. The proximity effect between two types of layers with different pairing symmetries can result in interesting novel phenomena. The time reversal symmetry may be broken with mixed s-wave and d-wave pairing symmetries.

Introducing additional carriers or applying external pressure in these materials can maximize $T_{c}$. For $\mathrm{Ba}_{2} \mathrm{CuO}_{2} \mathrm{Fe}_{2} \mathrm{As}_{2}$, the doping of $\mathrm{Fe}_{2} \mathrm{As}_{2}$ layer is 0.15 holes 
per $\mathrm{Fe}$ and that of $\mathrm{CuO}_{2}$ is 0.3 electrons per $\mathrm{Cu}$. The doping for $\mathrm{Fe}_{2} \mathrm{As}_{2}$ layer is near the optimal level but that for $\mathrm{CuO}_{2}$ layer is unfortunately not in the superconducting region. To realize superconductivity for both layers, we can introduce hole doping with partial replacement of $\mathrm{Ba}^{2+}$ ions by $\mathrm{K}^{+}$ ions. From the phase diagrams of cuprates and $(\mathrm{Ba}, \mathrm{K}) \mathrm{Fe}_{2} \mathrm{As}_{2}$, the above case can be realized in $\mathrm{Ba}_{2-x} \mathrm{~K}_{x} \mathrm{CuO}_{2} \mathrm{Fe}_{2} \mathrm{As}_{2}(0.24$ $\leq x \leq 0.32$ ) by assuming that the $\mathrm{Fe}_{2} \mathrm{As}_{2}$ and $\mathrm{CuO}_{2}$ layers are equally hole doped. In this doping region, the $\mathrm{T}_{c}$ for $\mathrm{Fe}_{2} \mathrm{As}_{2}$ layers shows little change. $x=0.3$ corresponds the optimal doping value for electron-doped cuprates ${ }^{14}$. For $\mathrm{K}_{2} \mathrm{CuO}_{2} \mathrm{Fe}_{2} \mathrm{Se}_{2}$, however, the $\mathrm{Fe}_{2} \mathrm{Se}_{2}$ layers are electron doped and the hole doping for $\mathrm{CuO}_{2}$ layers is not in superconducting region but very close to it. The superconductivity for both layers can be realized in $\mathrm{K}_{2-x} \mathrm{Ba}_{x} \mathrm{CuO}_{2} \mathrm{Fe}_{2} \mathrm{Se}_{2}(0.10$ $\leq x \leq 0.54)$. This doping region is much wider than that in $\mathrm{Ba}_{2} \mathrm{CuO}_{2} \mathrm{Fe}_{2} \mathrm{As}_{2}$ due to the wide hole-doped superconducting region in cuprates. The optimal doping value for $\mathrm{CuO}_{2}$ layers is $x=0.34$. The pressure is also an effective way to tune the superconductivity.

\section{CONCLUSION}

In conclusion, we identify two hypothetical compounds $\mathrm{Ba}_{2} \mathrm{CuO}_{2} \mathrm{Fe}_{2} \mathrm{As}_{2}$ and $\mathrm{K}_{2} \mathrm{CuO}_{2} \mathrm{Fe}_{2} \mathrm{Se}_{2}$ containing $\mathrm{Fe}_{2} \mathrm{X}_{2}$ layers and $\mathrm{CuO}_{2}$ layers, which are the basic structural units of
IBS and cuprates, respectively. The metallic spacer $\mathrm{Ba}(\mathrm{K})$ separates the basic units. The calculations of binding energies and phonon spectrums indicate that they are dynamically stable, ensuring that they may be experimentally synthesized. The Fermi surfaces derived from $\mathrm{Fe}_{2} \mathrm{As}_{2}\left(\mathrm{Fe}_{2} \mathrm{Se}_{2}\right)$ layers and $\mathrm{CuO}_{2}$ layers are very similar to those of iron pnictides (iron chalcogenides) and cuprates, respectively. With heavy selfdoping, the ground state of $\mathrm{Ba}_{2} \mathrm{CuO}_{2} \mathrm{Fe}_{2} \mathrm{As}_{2}$ is determined to be E-type collinear AFM state in the $\mathrm{Fe}_{2} \mathrm{As}_{2}$ layer and paramagnetic state in the $\mathrm{CuO}_{2}$ layer, while $\mathrm{K}_{2} \mathrm{CuO}_{2} \mathrm{Fe}_{2} \mathrm{Se}_{2}$ favors checkboard AFM state in $\mathrm{CuO}_{2}$ layers and paramagnetic state in $\mathrm{Fe}_{2} \mathrm{Se}_{2}$ layers. Without external doping, superconductivity can only be achieved in $\mathrm{Fe}_{2} \mathrm{X}_{2}$ layers. However, with external doping through substitution, superconductivity for both $\mathrm{Fe}_{2} \mathrm{X}_{2}$ and $\mathrm{CuO}_{2}$ layers can be simultaneously achieved in $\mathrm{Ba}_{2-x} \mathrm{~K}_{x} \mathrm{CuO}_{2} \mathrm{Fe}_{2} \mathrm{As}_{2}(0.24 \leq x \leq 0.32)$ and $\mathrm{K}_{2-x} \mathrm{Ba}_{x} \mathrm{CuO}_{2} \mathrm{Fe}_{2} \mathrm{Se}_{2}(0.10 \leq x \leq 0.54)$. The synthesis of these new compounds will not only provide us a unique opportunity to explore exotic properties in cuprates and IBS simultaneously but also help us to understand the mechanism of high $\mathrm{T}_{c}$ superconductivity.

Acknowledgments: The work is supported by the Ministry of Science and Technology of China 973 program( No. 2015CB921300), National Science Foundation of China (Grant No. NSFC-1190020, 11334012), and the Strategic Priority Research Program of CAS (Grant No. XDB07000000).
1 J. G. Bednorz and K. A. Muller, Z. Phys. B 64, 189 (1986).

${ }^{2}$ K. Kishio, K. Kitazawa, S. Kanbe, I. Yasuda, N. Sugii, H. Takagi, S. Uchida, K. Fueki and S. Tanaka, Chem. Lett. 2, 429(1987).

3 R. J. Cava, R. B. Dover, B. Batlogg and E. A. Rietman, Phys. Rev. Lett., 58, 408 (1987).

${ }^{4}$ R. M. Hazen, L. W. Finger, R. J. Angel, C. T. Prewitt, N. L. Ross, H. K. Mao and C. G. Hadidiacos, Phys. Rev. B 35, 7238 (1987).

${ }^{5}$ M. K. Wu, J. R. Ashburn, C. J. Torng, P. H. Hor, R. L. Meng, L. Gao, Z. J. Huang, Y. Q. Wang and C. W. Chu, Phys. Rev. Lett. 58, 908 (1987).

${ }^{6}$ H. Maeda, Y. Tanaka, M. Fukutomi and T. Asano, Jap. J. Appl. Phys. 27, L209 (1988).

7 Z. Z. Sheng and A. M. Hermann, Nature 332, 55 (1988).

8 A. Schilling, M. Cantoni, J. D. Guo and H. R. Ott, Nature 363, 56 (1993).

9 Y. Kamihara, T. Watanabe, M. Hirano and H. Hosnon, J. Am. Chem. Soc. 130, 3296 (2008).

10 J. H. Tapp, Z. Tang, B. Lv, K. Sasmal, B. Lorenz, P. C. W. Chu, and A. M. Guloy, Phys. Rev. B 78, 060505(R) (2008).

11 M. Rotter, M. Tegel, D. Johrendt, I. Schellenberg, W. Hermes and R. Pottgen, Phys. Rev. B 78, 020503(R) (2008).

${ }^{12}$ F. C. Hsu, J. Y. Luo, K. W. Yeh, T. K. Chen, T. W. Huang, P. M. Wu, Y. C. Lee, Y. L. Huang, Y. Y. Chu, D. C. Yan and M. K. Wu, Proc. Natl. Acad. Sci. U S A 105, 14262(2008).

13 J. G. Guo, S. F. Jin, G. Wang, S. C. Wang, K. X. Zhu, T. T. Zhou, M. He and X. L. Chen, Phys. Rev. B 82, 180520(R) (2008).

14 A. Damascelli, Z. Hussain and Z. X. Shen, Rev. Mod. Phys. 75, 473 (2003).

15 D. N. Basov and A. V. Chubukov, Nature Phys. 7, 272 (2011).

16 J. P. Hu and H. Ding, Sci. Rep. 2, 381 (2012).
${ }^{17}$ N. Barisic, M. K. Chan, Y. Li, G. Yu, X. Zhao, M. Dressel, A. Smontara and M. Greven, Proc. Natl. Acad. Sci. U.S.A. 110, 12235 (2013).

18 J. Paglione and R. L. Greene, Nature Phys. 6, 645 (2010).

19 D. J. Scalapino, Rev. Mod. Phys. 84, 1383 (2012)

20 A. Ricci, B. Joseph, N. Poccia, W. Xu, D. Chen, W. S. Chu, Z. Y. Wu, A. Marcelli, N. L. Saini and A. Bianconi, Supercond. Sci. Technol. 23, 052003 (2010).

21 T. T. Zhou, Y. M. Wang, S. F. Jin, D. D. Li, S. F. Lai, T. P. Ying, H. Zhang, S. J. Shen, W. J. Wang and X. L. Chen, Inorg. Chem. 53, 4154 (2014).

22 G. Kresse and J. Hafner, Phys. Rev. B 47, 558 (1993).

${ }^{23}$ G. Kresse and J. Furthmuller, Comput. Mater. Sci. 6, 15 (1996).

${ }^{24}$ G. Kresse and J. Furthmuller, Phys. Rev. B 54, 11169(1996).

25 J. P. Perdew, K. Burke and M. Ernzerhof, Phys. Rev. Lett. 77, 3865 (1996).

${ }^{26}$ M. T. Czyzyk and G. A. Sawatzky, Phys. Rev. B 49, 14211 (1994)

27 H. J. Monkhorst and J. Pack, Phys. Rev. B 13, 5188 (1976).

28 D. Alfe, Computer Physics Communications, 180, 2622 (2009).

29 A. Togo, F. Oba and I. Tanaka, Phys. Rev. B, 78, 134106 (2008).

${ }^{30}$ A. Togo and I. Tanaka, Scr. Mater., 108, 1 (2015).

31 Z. P. Yin, S. Lebegue, M. J. Han, B. P. Neal, S. Y. Savrasov and W. E. Pickett, Phys. Rev. Lett. 101, 047001 (2008).

${ }^{32}$ I. I. Mazin, M. D. Johannes, L. Boeri, K. Koepernik and D. J. Singh, Phys. Rev. B 78, 085104 (2008).

33 D. J. Singh, Phys. Rev. B. 78, 094511 (2008).

${ }^{34}$ D. J. Singh and M. H. Du, Phys. Rev. Lett. 100, 237003 (2008).

${ }^{35}$ H. Ding, P. Richard, K. Nakayama, T. Sugawara, T. Arakane, Y. Sekiba, A. Takayama, S. Souma, T. Sato, T. Takahashi, Z. Wang, X. Dai, Z. Fang, G. F. Chen, J. L. Luo and N. L. Wang, Europhys. 
Lett. 83, 47001 (2008).

${ }^{36}$ L. Zhao, H. Y. Liu, W. T. Zhang, J. Q. Meng, X. W. Jia, G. D. Liu, X. L. Dong, G. F. Chen, J. L. Luo, N. L. Wang, G. L. Wang, Y. Zhou, Y. Zhu, X. Y. Wang, Z. X. Zhao, Z. Y. Xu, C. T. Chen and X. J. Zhou, Chin. Phys. Lett. 25, 4402 (2008).

${ }^{37}$ K. Nakayama, T. Sato, P. Richard, Y. M. Xu, Y. Sekiba, S. Souma, G. F. Chen, J. L. Luo, N. L. Wang, H. Ding and T. Takahashi, Europhys. Lett. 85, 67002 (2009).

${ }^{38}$ C. Liu, G. D. Samolyuk, Y. Lee, N. Ni, T. Kondo, A. F. SantanderSyro, S. L. Budko, J. L. McChesney, E. Rotenberg, T. Valla, A. V. Fedorov, P. C. Canfield, B. N. Harmon and A. Kaminski, Phys. Rev. Lett. 101, 177005 (2008).

39 Y. M. Xu, P. Richard, K. Nakayama, T. Kawahara, Y. Sekiba, T. Qian, M. Neupane, S. Souma, T. Sato, T. Takahashi, H. Q. Luo,
H. H. Wen, G. F. Chen, N. L. Wang, Z. Wang, Z. Fang, X. Dai and H. Ding, Nat. Comm. 2, 392 (2011).

40 E. Akturk and S. Ciraci, Phys. Rev. B. 79, 184523 (2008).

41 A. Subedi, L. Zhang, D. J. Singh and M. H. Du, Phys. Rev. B 78, 134514 (2008).

${ }^{42}$ M. C. Lehman, A. Llobet, K. Horigane and D. Louca, J. Phys.: Conf. Ser. 251, 012009 (2010).

${ }^{43}$ Y. Zhang, L. X. Yang, M. Xu, Z. R. Ye, F. Chen, C. He, H. C. Xu, J. Jiang, B. P. Xie, J. J. Ying, X. F. Wang, X. H. Chen, J. P. Hu, M. Matsunami, S. Kimura and D. L. Feng, Nat. Mater. 10, 273 (2011).

${ }^{44}$ F. J. Ma, W. Ji, J. P. Hu, Z. Y. Lu and T. Xiang, Phys. Rev. Lett. 102, 177003 (2009). 